\title{
Grading Of Prostate Volume And International Prostatic Symptom Score (IPSS) In A Subset Of Karachi Population
}

\author{
Iffat Raza, Mahrukh Kamran, Sadaf Shaheen
}

ABSTRACT:

Objective: Analyze grading of IPSS (International Prostatic Symptom Score) and PV (Prostate Volume) of BPH patients in a subset of Karachi Population.

Methodology: A 103 Benign prostatic hyperplasia(BPH) patients were recruited. A cross-sectional study was done Prostate Volume was recorded along with their IPSS also noted.

Result: Among BPH patients $25.2 \%$ patients had prostate volume of 25 to $30 \mathrm{ml}, 52.5 \%$ of patient had prostate volume of 30 to $50 \mathrm{ml}$ and $22.3 \%$ of patients had prostate volume above $50 \mathrm{ml}$. In IPSS grading $82.5 \%$ patients were under moderate symptom group and $17.5 \%$ were under severe symptom group.

Conclusion: International Prostatic Symptom Score continues to increase as Prostate volume increases.

Key Words: International Prostatic Symptom Score (IPSS), Prostate volume (PV), Lower Urinary Tract Symptoms (LUTS)

INTRODUCTION:

Benign Prostatic Hyperplasia is a noncancerous enlargement of prostate gland. The disease can be assessed on two parameters. Objective and Subjective. "Objective parameters are prostate volume, urinary flow rate, determination of post void residue. Subjective parameters are incomplete emptying, frequency, intermittency, urgency, weak stream, straining and nocturia"

There are number of questionnaires available which assesses the symptoms of Benign Prostatic Hyperplasia. Some of these questionnaires are Boyarksky score, Madsen Iverson score, and Danish prostatic symptom score, International Prostatic Symptom Score(IPSS), Maine medical assessment score $)^{1}$.

Subjective parameters are used to quantify Lower Urinary Tract Symptoms (LUTS) as is assessed by International Prostate Symptom Score. As IPSS consists of seven questions. Each question consist of maximum 5 and minimum 0 score with a total score of IPSS constituting 35. World Health Organization has modified IPSS and severity of lower urinary tract symptoms is always graded as a mild symptom, moderate and severe symptom. On assessing the symptoms

Iffat Raza,
Assistant Professor, Anatomy Department,
Karachi Institute of Medical Sciences,
Combined Military Hospital Malir Cantt.
Email: razaiffat2@gmail.com
Mahrukh Kamran,
Assistant Professor, Anatomy Department,
Dow International Medical College,
Dow University of Health Sciences.
I Sadaf Shaheen
I Assistant Professor, Anatomy Department,
Shaheed Mohterma Benazir Bhutto Medical College, Lyari
I Karachi.
I Acceived: 04-09-18
| of LUTS patients were scored. A score of 0-7 comes under category of mild LUTS, 8-19 score has moderate LUTS and 20-35 score has severe symptoms as checked by IPSS score .

IPSS study was conducted by J.A. Chicharro et al in 1998, on 1106 men to correlate symptoms with $\mathrm{BPH}^{2}$. Results indicate that prostate volume increases with age as IPSS also increases and moderate lower urinary tract symptoms is perceived as poor quality of life ${ }^{3}$. Recently in a study conducted in Shanghai ${ }^{4}$ demonstrated usefulness of IPSS in the evaluation of BPH.

In clinical practice and research, the symptom severity of patient, as it is being assessed by prostate volume and negative impact of LUTS on patient life as assessed by IPSS should be accurately recorded. The dire need to assess and grade IPSS and Prostate volume in our subset of population is essential as all the therapeutic regimen like medications, surgeries and behavioural therapies will depend on reducing the severity of symptoms in patients and also alleviate the negative impact of LUTS on their life.

\section{METHODOLOGY:}

A cross sectional study was carried out in Ziauddin University Hospital, Karachi 2016. Samples were selected through convenience sampling. Target population was BPH patients aged 40 years and above with IPSS $>8$. An informed consent was obtained from each participant. After taking history an IPSS questionnaire was filled and IPSS was then calculated.

Patients with urinary retention status, prostatitis, Known case of prostatic carcinoma and on medications using 5alpha reductase inhibitors and anti-androgens were not included in this study. These subjects were excluded from the study by observing their past medical history or by patient clinical reports and as well as by abdominal ultrasound conducted for prostatic volume also helped to exclude kidney diseases along with above mentioned exclusion criteria. 
Sample size included 103 BPH patients. Out of them 37 were already diagnosed as BPH prior to ultrasonography from urology clinic, 50 volunteers with IPSS $>8$ and PV $>25 \mathrm{ml}$ fulfilling our study criteria were also included in this study as BPH patients.

Radiological assessment was carried out using Ultrasound machine, Toshiba Xario version 0.09, 3.5 Megahertz curvilinear transducer was used.

SPSS version 20 was used for analyzing statistics. Variables that were quantitative in nature was measured using ANOVA and Pearson correlation and Multinominal Regression. $<0.05$ $P$ value was taken as notable.

\section{RESULTS:}

In this study, BPH patients were categorized on the basis of their prostate volume. $\mathrm{PV}$ of $25-30 \mathrm{ml}$ were categorized as Grade 1, PV between $31-50 \mathrm{ml}$ were those subjects that were categorized as Grade 2, whereas Grade 3 were subjects between $51-93 \mathrm{ml}$ of prostate volume.

The table shows that using the total symptom score of each subject, 85 of them (82.5\%) experienced moderate lower urinary tract symptoms (LUTS) and 18 of them (17.5\%) experienced severe symptoms. Therefore, using IPSS, 103 BPH subjects had LUTS suggestive of BPH.

In order to check the association of IPSS (International Prostate Symptom Score) groups with PV (Prostate Volume). In this study, IPSS was divided into 2 groups according to the severity of symptoms of BPH patients i.e moderate and severe groups. Highest mean Prostate volume was found in IPSS severe score group as shown in table 3 . This was statistically significant (p-value 0.030 ).

There was progressive increase in IPSS scoring with mean prostate volume increasing from $40 \mathrm{ml}$ in moderate score group to $61 \mathrm{ml}$ in severe score group.

\begin{tabular}{|c|c|c|}
\hline GRADING OF PV (ml) & Frequency(n) & Percent \% \\
\hline Grade 1 - (25-30ml) & 26 & 25.2 \\
\hline Grade 2 - (31-50ml) & 54 & 52.5 \\
\hline Grade 3 - (51-93ml) & 23 & 22.3 \\
\hline Total & 103 & 100 \\
\hline
\end{tabular}

Table 1: Distribution of samples with respect to Grading of PV.

\begin{tabular}{|c|c|c|}
\hline Ipss Grading & Frequency(n) & Percent\% \\
\hline Moderate Score (8-19) & 85 & 82.5 \\
\hline Severe Score (20 Onwards) & 18 & 17.5 \\
\hline Total & 103 & 100 \\
\hline
\end{tabular}

Table 2: Distribution of BPH patients according to IPSS grading.

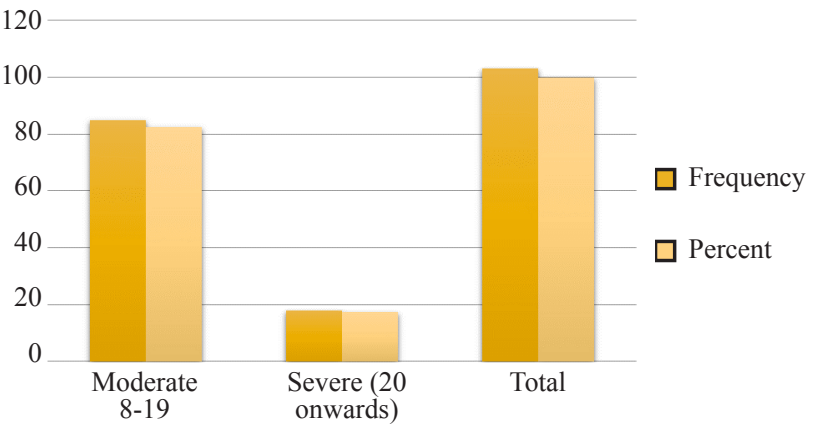

Figure 1. Severity of Symptoms

\begin{tabular}{|c|c|c|c|c|}
\hline IPSS groups & $\begin{array}{c}\text { Moderate } \\
\text { score (8-19) }\end{array}$ & $\begin{array}{c}\text { Severe score } \\
(20 \text { onwards })\end{array}$ & Total IPSS & p-value \\
\hline N & 85 & 18 & 103 & \multirow{2}{*}{$0.035^{*}$} \\
\cline { 1 - 4 } $\begin{array}{l}\text { Prostate } \\
\text { volume }(\mathrm{ml})\end{array}$ & $40.3 \pm 10.8$ & $61.1 \pm 19$ & $42.5 \pm 15.3$ & \\
\hline
\end{tabular}

Table 3: IPSS groups with respect to PV.

\section{DISCUSSION:}

In this sample of 103 patients, we found that 26 patients had 25 to $30 \mathrm{ml}$ of prostate volume (Table 1). Large number of patients were having 31 to $50 \mathrm{ml}$ of prostate volume in our study and only few patients reached 51 to $93 \mathrm{ml}$ of prostate volume with gross enlargement. A study by Collins et al found that 1627 patients showed maximum number of patients having the prostate volume ranging between 30 to $40 \mathrm{ml}^{5}$. Baswaraj et al found that $79 \%$ of BPH patients had prostate volume between 25 to $50 \mathrm{ml}$. This study is in accordance to above mentioned study as $80 \%$ of our population had prostate volume ranging between 25 to 50 $\mathrm{ml}^{6}$.

The need of grading of prostate volume is important as it helps urologist in decision making of the kind of treatment required by the BPH patients. Wang in his study reported, they designated their grading as a, b \& c. Grade a was patients with Prostate volume $<20 \mathrm{ml}$, Grade $b$ was prostate volume between 20 to $40 \mathrm{ml}$ and grade $\mathrm{c}$ was prostate volume greater than $40 \mathrm{ml}^{7}$.

Prostate volume size is crucial as it helps urosurgeons to decide small prostate size but median lobe enlargement needs surgical excision whereas large prostate size with no enlargement of median lobe can be treated by 5 alpha reductase inhibitors. Usually patients with $70 \mathrm{ml}$ or more requires suprapubic prostatectomies ${ }^{8}$.

In our study 85 number of patients were in the moderate symptom group. It follows therefore, that IPSS can be used to detect and determine the severity of BPH in order to select the most appropriate treatment group, while severe symptoms group were 18 patients as assessed by IPSS (Table 2). A Nigerian study in 2012 reported that $71 \%$ of their patients were in the moderate symptom group 9 . However, Overland 
et al. in their study found $23.6 \%$ of their patients had moderate symptoms and only $5 \%$ of the patients had severe symptoms ${ }^{10}$ IPSS increases with increasing Prostate Volume in our study as shown in table 3.

The variability of symptoms may be due to variable pattern of prostate enlargement. Excess growth in the transitional zone can produce enlargement without significant obstructive symptoms. On the other hand, periurethral enlargement or nodular growth can produce obstructive symptoms with no enlargement of gland as a whole ${ }^{11}$. IPSS increased with increasing prostate volume in our study as shown in table3.

This study also reported the association of Prostate volume with IPSS, notified that patients with IPSS of 8 to 19 which is a moderate group also has prostate volume of $40 \mathrm{ml}$ whereas severe score group which is 20 to 35 also has significantly increased prostate volume of $60 \mathrm{ml}$.

IPSS proves to be valuable tool in management of Benign prostatic hyperplasia. Patients falling in IPSS moderate symptom group with prostate volume enlargement of $>30$ $\mathrm{ml}$ and aged 50 years can be given treatment of 5 alpha reductase inhibitors ${ }^{12}$. Combination therapy of alpha blockers and 5 alpha reductase inhibitors is given to patients with LUTS along with prostatic enlargement, this combo drug helps in preventing urinary retention status as well as can delay surgeries of those patients who are reluctant to undergo surgery ${ }^{13}$. Patients with larger prostate volume along with falling in severe symptom group of IPSS requires Trans urethral resection of prostate (TURP) which serves to be a gold standard treatment in $\mathrm{BPH}^{14}$. However, open prostatectomies are for patients with larger prostate gland ,patients not fit for TURP with risk of excessive bleeding ${ }^{15}$. TUIP (transuretheral incision of prostatectomy) can be done for patients with prostate volume of $30 \mathrm{ml}$ or less having mild to moderate symptoms ${ }^{16,17}$. Minimally invasive surgeries like TUMT (trans uretheral microwave therapy) and TUNA (trans urethral needle ablation) ${ }^{18}$ are also preferably for younger patients falling in moderate symptom IPSS group with small to moderate size prostate gland ${ }^{19}$. IPSS is a simple document, a simple questionnaire should be present in urological clinics, simple affective tool in management of LUTS along with $\mathrm{BPH}^{20}$.

\section{CONCLUSION:}

Benign prostatic hyperplasia is most common disease afflicting aged men of our society. PV continues to increase so does the symptom score. IPSS can be an affective tool for health care providers in assessing degree of severity of symptoms of BPH patients, before recommending BPH patients for TAUS or TRUS

\section{REFERENCES:}

1. Omran M, Hassan E, Khalid KE \& Mohammed El Imam, MA. 2010. Evaluation of Application of International Prostate Symptoms Score in Sudanese Patients with Benign Prostatic Hyperplasia. Gezira Journal of Health Sciences, 6.
2. Chicharro-molero J., Burgos-rodriguez R., Sanchez-cruz J., Del Rosal-samaniego J., Rodero-carcia P. \& Rodriguez-vallejo J. 1998. Prevalence of benign prostatic hyperplasia in Spanish men 40 years old or older. The Journal of urology, 1998;159(3):878-82.

3. Berges R. \& Oelke M. 2011. Age-stratified normal values for prostate volume, PSA, maximum urinary flow rate, IPSS, and other LUTS/BPH indicators in the German male communitydwelling population aged 50 years or older. World journal of urology, 2011;29(2):171-178.

4. Zhang SJ, Qian HN., Zhao Y, Sun K, Wang HQ, Liang GQ, Li FH. \& Li Z. 2013. Relationship between age and prostate size. Asian journal of andrology, 2012;15(1): 116-20.

5. Collins G, Lee R, Mckelvie G, Rogers A \& Hehir M. 1993. Relationship between prostate specific antigen, prostate volume and age in the benign prostate. British journal of urology, 71, 445-450.

6. Basawaraj N. \& Arul Dasan T. 2012. Can sonographic prostate volume predicts prostate specific antigen (psa) levels in blood among non prostatic carcinoma patients?

7. Wang JY, Liu M, Zhang YG, Zeng P, Ding Q, Huang J, He DL, Song B, Kong CZ. \& Pang J. 2008. Relationship between lower urinary tract symptoms and objective measures of benign prostatic hyperplasia: a Chinese survey. Chin Med J (Engl), 2008;121(20): 2042-5.

8. Dmochowski RR. 2005. Bladder outlet obstruction: etiology and evaluation. Reviews in urology, 2005;7(6):3-13.

9. Amu OC, Udeh EI, Ugochukwu AI, Dakum NK \& Ramyil,VM. 2013. The value of international prostate symptom scoring system in the management of BPH in Jos, Nigeria. Nigerian journal of clinical practice, 2013;16(3): 273-8.

10. Overland G B, Vatten L, Rhodes T, Demuro C, Jacobsen G, Vada K, Angelsen A \& Girman C J. 2001. Lower urinary tract symptoms, prostate volume and uroflow in Norwegian community men. European urology, 2001;39:36-41.

11. Liu CC, Wang CJ, Huang SP, Chou YH, Wu WJ \& Huang, $\mathrm{CH}$. Relationships between American Urological Association symptom index, prostate volume, and disease-specific quality of life question in patients with benign prostatic hyperplasia. The Kaohsiung journal of medical sciences, 2004;20:273278.

12. Jeong CW, Park HK, Hong SK, Byun SS, Lee HJ \& Lee SE, 2008. Comparison of prostate volume measured by transrectal ultrasonography and MRI with the actual prostate volume measured after radical prostatectomy. Urologia internationalis, 2008;81:179-185.

13. Tanaka Y, Masumori N, Itoh N, Furuya S, Ogura H \& Tsukamoto T. 2006. Is the short-term outcome of transurethral resection of the prostate affected by preoperative degree of bladder outlet obstruction, status of detrusor contractility or detrusor overactivity? International journal of urology, 2006;13:1398-1404.

14. Tsukamoto T, Masumori N, Nakagawa H, Arai Y, Komiya A, Ichikawa T, Takei M, Yamaguchi A, Liu Y \& Crane MM. 2009. Changes in prostate volume in Japanese patients with benign prostatic hyperplasia: association with other urological measures and risk of surgical intervention. International journal of urology, 2009;16:622-627.

15. Tsukamoto T, Masumori N, Rahman M \& Crane MM. Change in International Prostate Symptom Score, prostrate-specific antigen and prostate volume in patients with benign prostatic 
hyperplasia followed longitudinally. International journal of urology, 2007;14:321-4.

16. Tuncay Aki F, Aygun C, Bilir N, Erkan I \& Ozen H. Prevalence of lower urinary tract symptoms in a community-based survey of men in Turkey. International journal of urology, 2003;10:364-370.

17. Turkbey B, Huang R, Vourganti S, Trivedi H, Bernardo M, Yan P, Benjamin C, Pinto PA \& Choyke PL. Age-related changes in prostate zonal volumes as measured by highresolution magnetic resonance imaging (MRI): a crosssectional study in over 500 patients. BJU international, 2012;110(11):1642-47.
18. Unsal A, Ayranci U \& Tozun M. 2010. Prevalence of lower urinary tract symptoms among men in a rural district of western Turkey. Pak J Med Sci, 2010;26: 294-9.

19. Zhang SJ, Qian HN, Zhao Y, Sun K, Wang HQ, Liang GQ, Li FH \& Li Z. Relationship between age and prostate size. Asian journal of andrology, 2013;15(1):116-120

20. Van Dijk MM, Wijkstra H, Debruyne FM, De La Rosette, JJ. $\&$ Michel MC. The role of nocturia in the quality of life of men with lower urinary tract symptoms. BJU international, 2010;105:1141-46.

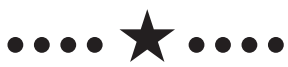

